Article

\title{
Germination of Chloris barbata, Cynodon dactylon, and Cyperus rotundus from Angola at Constant and Alternate Temperatures
}

\author{
Donato Loddo $^{1, *(\mathbb{D} \text {, Stefano Carlesi }}{ }^{2}$ and Adérito Tomás Pais da Cunha ${ }^{3,4}$ \\ 1 Institute for Sustainable Plant Protection, National Research Council of Italy, 35020 Legnaro, Italy \\ 2 Institute of Life Sciences, Sant'Anna School of Advanced Studies, 56127 Pisa, Italy; s.carlesi@santannapisa.it \\ 3 Departamento de Agronomia, Instituto Superior Politécnico do Kwanza sul, Sumbe, Angola; \\ aderito.cunha@ciencia.ao \\ 4 Centro Nacional de Investigação Científica (CNIC), Luanda, Angola \\ * Correspondence: donato.loddo@cnr.it; Tel.: +39-049-8272-822
}

Received: 17 September 2019; Accepted: 1 October 2019; Published: 7 October 2019

\begin{abstract}
The study of weed germination can improve knowledge on their seasonal dynamics in fields and facilitate the design of ecologically sustainable management. An experiment was conducted to evaluate the effect of a range of constant and alternate temperatures on the germination of Chloris barbata, Cynodon dactylon, and Cyperus rotundus collected in Angola. Interesting differences were observed between the germination responses of the three species. No germination was observed for any species at 10 or $15-5^{\circ} \mathrm{C}$. Chloris barbata quickly germinated at most constant and alternate incubation temperatures, showing low primary dormancy and high germinability. Fast and high germination was observed for Cynodon dactylon at most alternate temperatures, while lower germination percentages were achieved at constant temperatures, especially the highest ones. Cyperus rotundus achieved good germination percentage at alternate temperatures, even if with slower and more extended germination dynamics than the other species, while almost no seeds germinated at constant temperatures. This study improves our knowledge of germination ecology for these species and allows some control tools to be identified, such as soil tillage, cover crops, and living or dead mulches, which can contribute to their ecologically sustainable management.
\end{abstract}

Keywords: Chloris barbata; Cynodon dactylon; Cyperus rotundus; germination; integrated weed management; sustainable weed management; sustainable food production

\section{Introduction}

Weeds are a major constraint for crop production and, among crop pests, are responsible for the highest potential yield losses [1]. In the absence of adequate control measures, weeds are estimated to cause an average of 50\% yield loss for maize and soybean in North America [2,3]. Similar results were reported in various studies from European countries [4,5], and even higher losses were observed for maize, sorghum, and rice in Africa [6-8]. Herbicide application and soil tillage are the most commonly adopted and effective weed control measures for modern agriculture systems, but the situation is completely different in developing countries. Due to the lack of available machinery, pesticides, and trained operators, weed management in Africa is largely based on hand weeding [9], requiring an impressive amount of labour, estimated at more than $300 \mathrm{~h} / \mathrm{ha}$ in sorghum [7] to achieve satisfactory weed control. Given the obvious difficulties in conducting such a labour-intensive operation promptly on all fields, hand weeding is often not performed at the right time or to the right extent leading to not optimal weed control. Consequently, the presence of competitive weed species is a common constraint for small farmers, causing important yield losses [9] and limiting the size of their farms [10] 
due to the amount of labour required for weeding. Herbicides can strongly contribute to more efficient and effective weed control, but management strategies should not over-rely on those tools to ensure long-term sustainability. Environmental contamination and impacts on different organisms are frequently reported in several cropping systems worldwide [11-13], and risks correlated to excessive or not appropriate herbicide use could be higher in many developing countries due to a lack of trained operators and the modern equipment necessary to guarantee safe pesticide application. Weed control strategies based on repeated herbicide use alone can be very effective and convenient in the short-term but lead progressively to the selection of competitive weed floras and the evolution of herbicide-resistant biotypes [14-16]. Adopting multi-tactic approaches, based on the combination of herbicide use with mechanical, physical, and cultural tools, is therefore important to diversify the selection pressure on weed flora, avoiding the progressive dominance of a few adapted species, and achieve long-term sustainability of weed management [17-19].

In order to limit population growth and weed competition, management should focus on the crucial phases of the life cycle of weeds, i.e., the germination-emergence phase for annual species when they can rely only upon the limited seed resources to survive. However, germination is also an important phase for perennial species because seed dissemination is their main dispersal strategy, which allows rapid field colonization by creating new patches at a given distance from the mother plants. Weed-crop competition and, consequently, the potential yield loss caused by weeds are strongly affected by the timing and magnitude of weed germination and emergence [20], and several management tactics were studied and adopted to promote or hinder weed germination. Surface soil disturbance can promote weed germination and emergence [21,22], while seed burial due to tillage can notably reduce germination [23]. Cover crop or cash crop residues can inhibit weed germination due to allelopathic effects, if incorporated in the soil, or by reducing soil temperature fluctuation and light penetration, if left on the soil surface as dead mulch $[24,25]$. However, since contrasting responses to these tactics were observed for the different species, it is important to acquire knowledge on germination ecology and environmental control of germination for the main weeds of a given cropping system, to identify the most appropriate tactics for their management. Soil temperature is considered one of the main environmental factors controlling seed dormancy and germination and determining seasonal periodicity of weed germination and emergence [26]. In particular, exposure to fluctuating temperatures was reported to notably promote germination for many weed species, especially for the small-seeded ones [27,28]. This behaviour is explained from an ecological point of view as a strategy to perceive canopy gaps and shallow burial depth, given that fluctuation of soil temperature increases in the absence of canopy covering and close to the soil surface $[29,30]$, which is a favourable condition for seedling emergence and growth.

During periodic surveys of weed flora in the area of Sumbe, which is located along the Atlantic coast of Angola in the Southern African subregion, the species Chloris barbata Sw. (purpletop chloris, Poaceae), Cynodon dactylon L. (Pers.) (Bermuda grass, Poaceae), and Cyperus rotundus L. (purple nutsedge, Cyperaceae) were often reported to be spreading into cultivated fields and causing economic losses to different crops (Pais da Cunha, personal communication). Chloris barbata is an annual or short-lived perennial species that is propagated by seeds and described as an important weed in many tropical and subtropical regions [31,32]. Different species of the Chloris genus are troublesome weeds in different cropping systems worldwide, and herbicide-resistant biotypes are also reported [33,34]. Cynodon dactylon and C. rotundus are two perennial species included among the most problematic and dangerous weeds worldwide $[31,32,35]$. Both species rely mainly on vegetative reproduction-C. dactylon by rhizomes and stolons and C. rotundus by tubers and rhizomes-for short-range multiplication; however, seed dissemination is an important process for their long-term dispersion and the colonization of new fields. Since limited information is available on the germination ecology of these three important species in Africa in general, a study was conducted to assess the effect of temperature on germination of seed batches of C. barbata, C. dactylon, and C. rotundus collected in the area of Sumbe, Angola. This 
study is part of a wider project whose overall objective is to acquire information on the biology and ecology of the main weed species in that area, in order to design specific management strategies.

\section{Materials and Methods}

\subsection{Seed Collection and Storage}

Seeds of C. barbata, C. dactylon, and C. rotundus were collected in the Sumbe area $\left(11^{\circ} 11^{\prime} 42^{\prime \prime}\right.$ S, $13^{\circ} 50^{\prime} 51^{\prime \prime} \mathrm{E}, 10 \mathrm{~m}$ above sea level (MASL), Cuanza Sul, Angola), close to the Atlantic Ocean. The local climate is classified as BSh (main climate B: arid, precipitation S: steppe, temperature h: hot arid), according to the updated Köppen-Geiger classification [36]. The average temperature is $24^{\circ} \mathrm{C}$, July is the coolest month (average temperature $20^{\circ} \mathrm{C}$ ), and March is the warmest month (average temperature $26^{\circ} \mathrm{C}$ ). Annual precipitation is less than $450 \mathrm{~mm}$, distributed mainly in March, April, and November, while almost no rainfalls occur from June to August. Main field crops in the area are maize, cassava, sweet potato, vegetables, beans, peanuts, tomato, and, more recently, sunflower and soybean. The soil is mainly acid clay soil. Seeds were collected from several plants to have a representative sample of the intra-population variability. Seeds were cleaned and left to dry at room temperature $\left(20^{\circ} \mathrm{C}\right)$ for 2 weeks and then stored for two months in paper bags at $4{ }^{\circ} \mathrm{C}$ until the start of the experiment to minimize modification of dormancy level. Storage duration and conditions were the same for all three species. Seed weight (expressed as 1000-seed weight) was measured by weighing three replicates of 1000 seeds each per species. The three species are characterized by small seeds, the 1000-seed weight being $0.22 \pm 0.010 \mathrm{~g}$ for C. barbata, $0.03 \pm 0.001 \mathrm{~g}$ for C. dactylon, and $0.38 \pm 0.010 \mathrm{~g}$ for C. rotundus.

\subsection{Germination Test}

Seeds of the three species were placed in plastic Petri dishes on filter paper imbibed with $3 \mathrm{~mL}$ of deionized water. The Petri dishes were incubated in germination chambers at a set of $(10,15,20,25$, and $\left.30{ }^{\circ} \mathrm{C}\right)$ or alternate $\left(15-5,20-10,25-15,30-20\right.$ and $\left.35-25^{\circ} \mathrm{C}\right)$ temperatures and a $12 \mathrm{~h}$ light photoperiod, with neon tubes providing a photosynthetic photon flux density (PPFD) of $15-30 \mu \mathrm{mol} \mathrm{m}^{-2} \mathrm{~s}^{-1}$. In the case of alternate temperatures, the highest temperature corresponded with the light period. Three replicates, i.e., three Petri dishes of 50 seeds, were included for each treatment (species * incubation temperature), and the experiment was repeated twice. Germinated seeds, i.e., those with a visible emerging radicle $(>1 \mathrm{~mm})$, were counted and removed daily. Tests were ended when no further germination was observed for 21 days. Germination tests lasted from 2 to 5 months, according to incubating temperatures. Viability of non-germinated seeds was assessed with an imbibed seed-crush test [37]. Seeds considered as nonviable were excluded from the data analyses, and the germination percentage of each replicate was calculated on the total of germinated plus non-germinated viable seeds.

\subsection{Statistical Analysis}

Mean and SE were calculated for the germination percentage of each treatment (considering the data from the six replications). To focus on the interaction between temperature and thermal mode (constant vs. alternate), raw data on germination percentage were analysed for each species, using a generalised mixed model with a binomial distribution, assuming the germination percentage as the probability of a single seed to germinate or not, till the end of the test. The random part of the model consisted of a nested design; the three replicates were nested within the two experiments. The fixed part of the model consisted of temperature and thermal mode (constant vs. alternate) as factors. The significance of the two factors and the interaction among those and the species were tested performing a three-way ANOVA. Models were created using lme4 [38], post hoc tests were conducted using emmeans [39], residual overdispersion was tested using DHARMa nonparametric overdispersion test, and homogeneity of residuals was tested using a Kolmogorov-Smirnov test on 1000-time resampled residuals, using DHARMa [40] packages for R 3.3.2 [41]. 


\section{Results}

\section{Effect of Temperature on Germination}

No germination was observed for any species at 10 or $15-5{ }^{\circ} \mathrm{C}$ (Figure 1 ), and, consequently, the values corresponding to those treatments were removed from the post hoc analysis because it was not possible to calculate any variance due to the absence of variability in the data collected. The ANOVA of the Max germination percentage showed a significant three-way interaction (species * temperature * thermal mode), just as all the two-way interactions tested did (Table 1). The Max germination percentage for the three species resulted as significantly different for each one, following different patterns concerning incubation temperature and thermal mode. C. barbata germinated well at all alternate temperatures, apart from the $15-5{ }^{\circ} \mathrm{C}$ treatment, and no significant differences $(P>0.05)$ were observed between the different treatments $\left(20-10,25-15,30-20\right.$, and $\left.35-25^{\circ} \mathrm{C}\right)$. Concerning the treatments at constant temperatures, the germination percentage obtained at $15^{\circ} \mathrm{C}$ resulted significantly lower than at $25^{\circ} \mathrm{C}$ and $30^{\circ} \mathrm{C}(P<0.0128$ and $P<0.0221$, respectively $)$, while, at $20^{\circ} \mathrm{C}$, it reached an intermediate value without significant differences with the other incubation temperatures. The first germinated seeds were observed at 2-7 days after sowing (DAS) at all temperatures, and germination lasted until 15-46 DAS (Figure 2). Even if similar germination percentages were obtained with alternate and constant temperatures, germination speed was lower and, consequently, the duration longer, at constant temperatures. In particular, at $15^{\circ} \mathrm{C}$, an initial lag phase of six days was observed before germination started, and it lasted until 46 DAS. Regarding $C$. dactylon, germination percentage showed different trends at the two thermal modes. Lower percentages were obtained with constant temperatures than with alternate temperatures. At constant temperatures, the higher germination percentages were observed at 15 and $20{ }^{\circ} \mathrm{C}$, while significantly lower values were obtained at 25 and $30^{\circ} \mathrm{C}(P<0.008)$. On the contrary, considering the treatments with alternate temperatures, the germination percentage showed a positive trend with the increase of incubation temperature. The highest value was observed at $35-25^{\circ} \mathrm{C}$, with significant differences from 20 to $10{ }^{\circ} \mathrm{C}(P<0.001)$, but not $25-15$ or $30-20^{\circ} \mathrm{C}(P>0.05)$. The start of germination was fast, with the first germinated seeds observed at 2-14 DAS for 35-25 and $15^{\circ} \mathrm{C}$, respectively, and lasted until 11-42 DAS (Figure 3). The thermal mode affected germination dynamics at low temperatures, i.e., germination was faster with the alternate temperature. Indeed, germination occurred between 10 and 25 DAS at $20-10{ }^{\circ} \mathrm{C}$ and between 14 and $42 \mathrm{DAS}$ at the corresponding $15^{\circ} \mathrm{C}$. The germination percentage of $C$. rotundus was deeply affected by thermal mode. The highest germination percentage reached with constant temperatures was only about $1 \%$ and was significantly lower $(P<0.001)$ than all the treatments with alternate temperatures, apart from 15 to $5{ }^{\circ} \mathrm{C}$. Considering the alternate temperatures, the highest germination percentage was reached at $25-15^{\circ} \mathrm{C}$, with significant differences from 20 to $10^{\circ} \mathrm{C}(P=0.0009)$ and from 35 to $25^{\circ} \mathrm{C}(P=0.0037)$, but not from 30 to $20^{\circ} \mathrm{C}(P=0.3174)$. Slower and more extended germination dynamics were observed for $C$. rotundus in comparison with the other two species (Figure 4). The first germinated seeds were observed at 11-34 DAS, and germination lasted until 70-130 DAS at 35-25 and $20-10{ }^{\circ} \mathrm{C}$, respectively. 


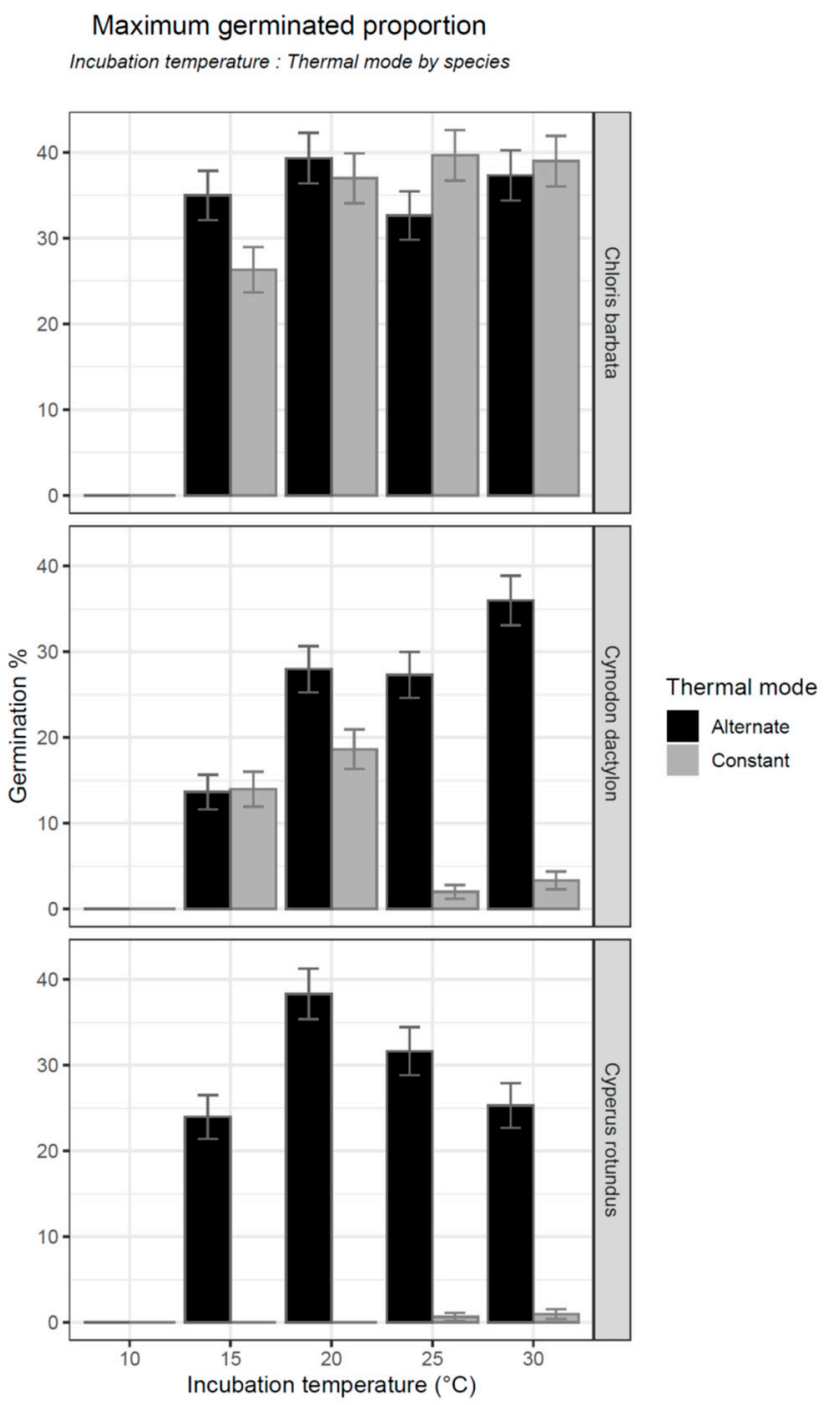

Figure 1. Figure 1 Germination percentage at the different incubation temperatures $\times$ thermal mode interactions for each species. Values are means of six replicates, and error bars represent the standard error (SE) (significance of the factors expressed are reported in Table 1). For the treatments with alternate temperatures, the mean of the range is reported (10 for 15-5, 15 for 20-10, 20 for 25-15, 25 for $30-20$, and 30 for $35-25^{\circ} \mathrm{C}$, respectively).

Table 1. Table 1 Three-way ANOVA results on the germination percentage. Effect of each of the three fixed factors (incubation temperature, thermal mode, and species) and their interactions are reported.

\begin{tabular}{cccc}
\hline Term & Chi Sq. & df & $\boldsymbol{P}$ Value \\
\hline Species & 272,102 & 14 & $<0.001$ \\
Incubation temperature & 127,326 & 17 & $<0.001$ \\
Thermal mode & 197,095 & 10 & $<0.001$ \\
Species: Incubation temperature & 91,447 & 12 & $<0.001$ \\
Species: Thermal mode & 164,258 & 6 & $<0.001$ \\
Incubation temperature: Thermal mode & 80,546 & 8 & $<0.001$ \\
Species: Incubation temperature: Thermal mode & 76,001 & 8 & $<0.001$ \\
\hline
\end{tabular}



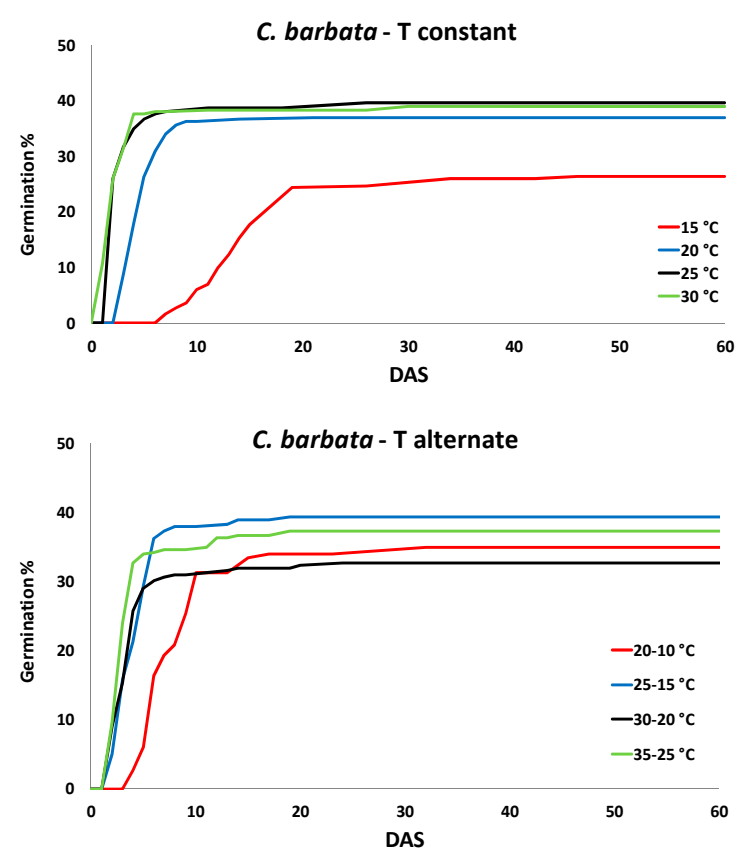

Figure 2. Germination dynamics of Chloris barbata at the different constant (above) and alternate (below) incubation temperatures. Values are means of six replicates, and DAS indicates day after sowing.
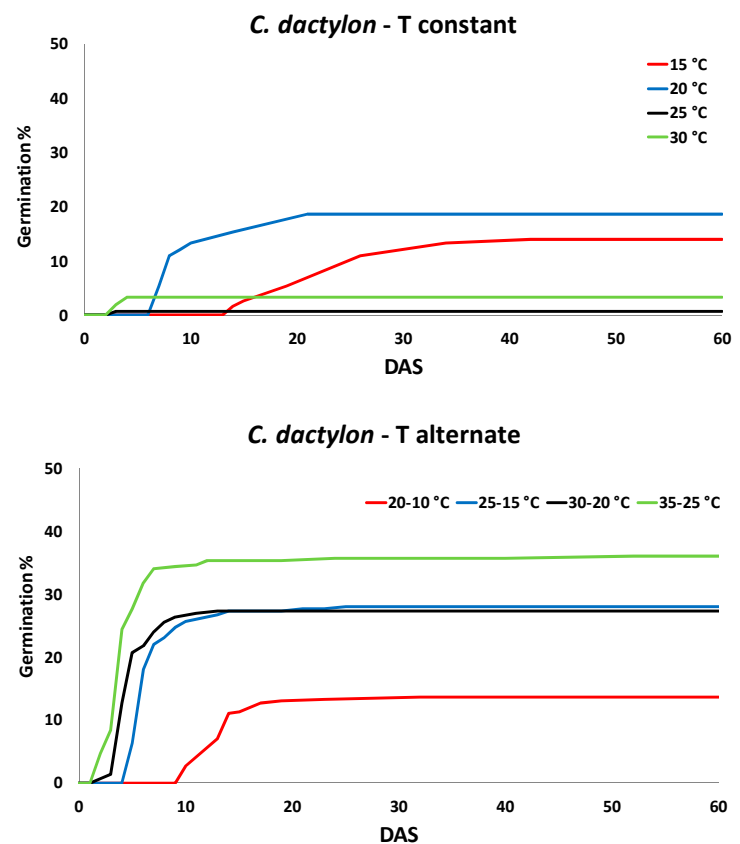

Figure 3. Germination dynamics of Cynodon dactylon at the different constant (above) and alternate (below) incubation temperatures. Values are means of six replicates, and DAS indicates days after sowing. 


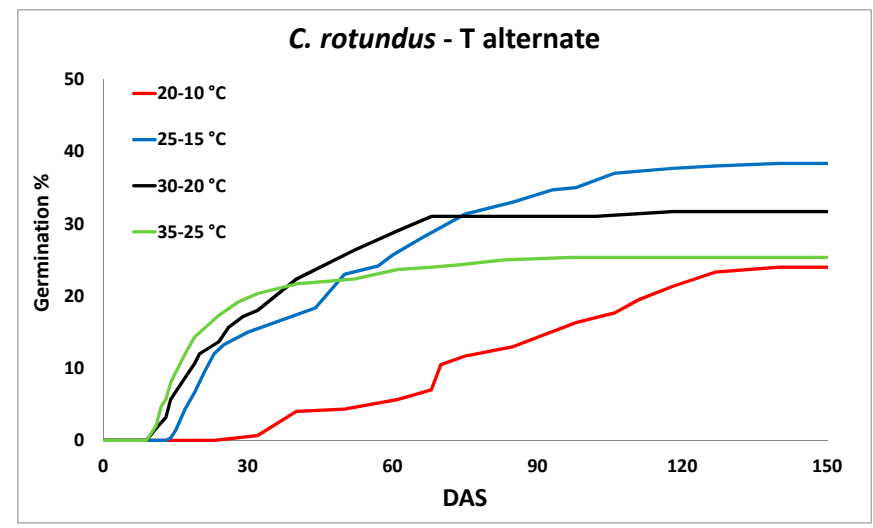

Figure 4. Germination dynamics of Cyperus rotundus at the different alternate incubation temperatures. Data regarding treatments at constant temperatures are not shown since germination was almost null. Values are means of six replicates, and DAS indicates days after sowing.

\section{Discussion}

Interesting differences can be underlined between germination ecology of the three species, leading to important indications on effective management tactics for their control. C. barbata seeds probably had a low primary dormancy and high germinability and were able to quickly germinate at all incubation temperatures, apart from $10^{\circ} \mathrm{C}$ and $15-5{ }^{\circ} \mathrm{C}$, so its base temperature for germination should be in the $15-10^{\circ} \mathrm{C}$ range. This behaviour is similar with what was reported for other Chloris species from Australia, namely C. truncata and C. virgata, even if those two species were able to germinate at $10{ }^{\circ} \mathrm{C}$ [42-44]. Given that temperatures in the Sumbe area are normally above the base temperature for $C$. barbata, germination can therefore occur all year around, soon after soil moisture allows seed imbibition (i.e., after rainfall or irrigation). C. dactylon seeds were able to germinate quickly at all alternate temperatures, apart from the $15-5{ }^{\circ} \mathrm{C}$ treatment, while lower germination percentages were achieved at constant temperatures, especially at 25 and $30^{\circ} \mathrm{C}$, and no germination was observed at $10^{\circ} \mathrm{C}$. Similar results and promoting effects of alternate temperatures on C. dactylon germination were described for several seed lots from the US $[45,46]$. Low seed dormancy level can be supposed for the C. dactylon population included in the present study, confirming the previous report by Veenendaal and Ernst [47] on a population from Botswana. C. rotundus achieved good germination percentage, showing its potential ability to also reproduce by seeds, contrary to what was previously stated by Thullen and Keeley [48], but only at alternate temperatures, while almost no germination was observed at constant temperatures. The requirement of fluctuating temperatures to promote seed germination is common among weed species colonizing cultivated fields [28]; this is considered to be an ecological strategy that allows germination only in particularly favourable conditions, i.e., seed position close to soil surface and absence of already-developed canopy, for the successive seedling establishment and growth. C. rotundus presented, in comparison with the other two studied species, a delayed start of germination, with the first germinated seeds observed after $30 \mathrm{DAS}$ at $20-10^{\circ} \mathrm{C}$, but a more prolonged period of germination that reached almost three months (from 30 to 120 DAS) at $20-10^{\circ} \mathrm{C}$.

Seeds of $C$. rotundus probably have a certain level of primary dormancy and are not able to germinate promptly after field dissemination. This could provoke delayed and extended flushes of seedling emergence during the cropping season, causing lower competition to the crop than early emerging species, but making it difficult to achieve total control. Some seedlings are likely to emerge after control operations, e.g., herbicide application or soil cultivation, which are usually performed in the first phases of the crop cycle, and can, therefore, grow and produce new seeds. Late-season control tactics should be considered for this species, in addition to other cultural methods, e.g., the choice of competitive crop cultivars to minimize weed-seed production and maintain soil seed bank at low levels. C. barbata and C. dactylon, having non-dormant seeds, can produce high germination percentages and relevant seedling emergence early in the cropping season and consequently cause 
strong weed competition against crops. However, early emerging species can effectively be targeted by several different tactics, such as the stale seedbed technique, pre-emergence and post-emergence herbicides, and mechanical control so that achieving optimal control of all emerged seedlings is feasible. Moreover, species that have seeds with a low dormancy level, such as C. barbata and C. dactylon, can hardly establish a persistent soil seed bank, so the size of field populations can be strongly reduced in a few years if further dissemination is avoided.

Given the small seed size of $C$. rotundus, C. barbata, and C. dactylon, seed burial in the soil can strongly reduce seedling emergence. Previous studies have described relevant inhibition of seedling emergence from seeds below $5 \mathrm{~cm}$ of depth, even for weed species with larger seed size, such as Alopecurus myosuroides Huds., Digitaria sanguinalis (L.) Scop., Echinochloa crus-galli (L.) Beauv., or Setaria viridis (L.) Beauv. [23,49]. Moreover, daily thermal fluctuations are limited at $5 \mathrm{~cm}$ of depth in comparison to the soil surface, and these conditions could inhibit species like $C$. rotundus, which require alternate temperatures to germinate [30]. Periodic soil tillage (e.g., shallow ploughing every three years), performed after seed dissemination, can be an effective tool to reduce seedling emergence for the studied species and promote seed bank depletion in the case of C. barbata and C. dactylon. Maintaining the soil covered by a layer of crop residues or by a dead mulch of cover crop can contribute to suppress weed germination by modifying soil conditions (reduced light transmittance and temperature fluctuations) or by allelopathic effect [50,51]. Small-seeded species, such as the ones included in this study, are more sensitive to allelopathic effects [52], which can also be obtained by soil incorporation of residues of cover crops, such as winter rye or oilseed rape, so allelopathy should be considered as an interesting tactic for C. rotundus, C. barbata, and C. dactylon.

This study contributes to the improvement of our knowledge on biology and particularly seed germination of $C$. rotundus, C. barbata, and C. dactylon. However, these findings should be combined with further studies on potential cultural control methods, mechanical tools, and cover crop management, because only the integration of different tactics can provide efficient control with low herbicide use for problematic weed species [53,54]. An efficient integrated weed management is necessary to support a long-term sustainable and feasible increase of crop productivity in the study area of Sumbe, Angola.

Author Contributions: Conceptualization, D.L. and A.T.P.d.C.; data curation, D.L. and S.C.; formal analysis, D.L. and S.C.; funding acquisition, A.T.P.d.C.; investigation, D.L. and A.T.P.d.C.; methodology, S.C.; project administration, A.T.P.d.C.; resources, D.L. and A.T.P.d.C.; supervision, A.T.P.d.C.; visualization, D.L. and S.C.; writing-original draft, D.L. and S.C.; writing—review and editing, D.L., S.C., and A.T.P.d.C.

Funding: This research received no external funding.

Acknowledgments: The authors are grateful to Alison Garside for revising the English text.

Conflicts of Interest: The authors declare no conflicts of interest.

\section{References}

1. Oerke, E.C. Crop losses to pests. J. Agric. Sci. 2006, 144, 31-43. [CrossRef]

2. Soltani, N.; Dille, J.A.; Burke, I.C.; Everman, W.J.; VanGessel, M.J.; Davis, V.M.; Sikkema, P.H. Potential corn yield losses from weeds in North America. Weed Technol. 2016, 30, 979-984. [CrossRef]

3. Soltani, N.; Dille, J.A.; Burke, I.C.; Everman, W.J.; Van Gessel, M.J.; Davis, V.M.; Sikkema, P.H. Perspectives on potential soybean yield losses from weeds in North America. Weed Technol. 2017, 31, 148-154. [CrossRef]

4. Otto, S.; Masin, R.; Casari, G.; Zanin, G. Weed-corn competition parameters in late-winter sowing in Northern Italy. Weed Sci. 2009, 57, 194-201. [CrossRef]

5. Lehoczky, E.; Nagy, P.; Lencse, T.; Tóth, V.; Kismányoky, A. Investigation of the damage caused by weeds competing with maize for nutrients. Commun. Soil Sci. Plant Anal. 2009, 40, 879-888. [CrossRef]

6. Chikoye, D.; Schulz, S.; Ekeleme, F. Evaluation of integrated weed management practices for maize in the northern Guinea savanna of Nigeria. Crop Prot. 2004, 23, 895-900. [CrossRef]

7. Ishaya, D.B.; Dadari, S.A.; Shebayan, J.A.Y. Evaluation of herbicides for weed control in sorghum (Sorghum bicolour) in Nigeria. Crop Prot. 2007, 26, 1697-1701. [CrossRef] 
8. Johnson, D.E.; Wopereis, M.C.S.; Mbodj, D.; Diallo, S.; Powers, S.; Haefele, S.M. Timing of weed management and yield losses due to weeds in irrigated rice in the Sahel. Field Crops Res. 2004, 85, 31-42. [CrossRef]

9. Vissoh, P.V.; Gbèhounou, G.; Ahanchédé, A.; Kuyper, T.W.; Röling, N.G. Weeds as agricultural constraint to farmers in Benin: Results of a diagnostic study. NJAS 2004, 52, 305-329. [CrossRef]

10. Kent, R.; Johnson, D.E.; Becker, M. The influences of cropping system on weed communities of rice in Côte d'Ivoire, West Africa. Agric. Ecosyst. Environ. 2001, 87, 299-307. [CrossRef]

11. Rohr, J.R.; McCoy, K.A. A qualitative meta-analysis reveals consistent effects of atrazine on freshwater fish and amphibians. Environ. Health Persp. 2010, 118, 20-32. [CrossRef] [PubMed]

12. Narushima, T.; Sato, T.; Goto, Y.; Takahashi, Y. Pesticides in river and tap water in rice production area of Niigata, Japan. Water Air Soil Pollut. 2014, 225, 2229. [CrossRef]

13. Boutin, C.; Stranberg, B.; Carpenter, D.; Mathiassen, S.K.; Thomas, P.J. Herbicide impact on non-target plant reproduction: What are the toxicological and ecological implications? Environ. Pollut. 2014, 185, 295-306. [CrossRef] [PubMed]

14. Owen, M.J.; Martinez, N.J.; Powles, S.B. Multiple herbicide-resistant Lolium rigidum (annual ryegrass) now dominates across the Western Australia grain belt. Weed Res. 2014, 54, 314-324. [CrossRef]

15. Ward, S.M.; Webster, T.M.; Steckel, L.E. Palmer amaranth (Amaranthus palmerii): A review. Weed Tech. 2013, 27, 12-27. [CrossRef]

16. Harker, K.N.; Mallory-Smith, C.; Maxwell, B.D.; Mortensen, D.A.; Smith, R.G. Another view. Weed Sci. 2017, 65, 203-205. [CrossRef]

17. Davis, A.S.; Hill, J.D.; Chase, C.A.; Johanns, A.M.; Liebmann, M. Increasing cropping system diversity balances productivity, profitability and environmental health. PLoS ONE 2012, 7, e47149. [CrossRef]

18. Liebman, M.; Baraibar, B.; Buckley, Y.; Childs, D.; Christensen, S.; Cousens, R.; Eizenberg, H.; Heijting, S.; Loddo, D.; Merotto, A., Jr.; et al. Ecologically sustainable weed management: How do we get from proof-of-concept to adoption? Ecol. Appl. 2016, 26, 1352-1369. [CrossRef]

19. Neve, P.; Barney, J.N.; Buckley, Y.; Cousens, R.D.; Graham, S.; Jordan, N.R.; Lawton-Rauh, A.; Liebman, M.; Mesgaran, M.B.; Schut, M.; et al. Reviewing research priorities in weed ecology, evolution and management: A horizon scan. Weed Res. 2018, 58, 250-258. [CrossRef]

20. Berti, A.; Sattin, M.; Baldoni, G.; Del Pino, A.M.; Ferrero, A.; Montemurro, P.; Tei, F.; Viggiani, P.; Zanin, G. Relationships between crop yield and weed time of emergence/removal: Modelling and parameter stability across environments. Weed Res. 2008, 48, 378-388. [CrossRef]

21. Riemens, M.M.; Van der Weide, R.Y.; Bleeker, P.O.; Lotz, L.A.P. Effect of stale seedbed preparations and subsequent weed control in lettuce (cv. Iceboll) on weed densities. Weed Res. 2007, 47, 149-156. [CrossRef]

22. Schutte, B.J.; Tomasek, B.J.; Andersson, L.; Andersson, L.; Benoit, D.L.; Cirujeda, A.; Dekker, J.; Forcella, F.; Gonzalez-Andujar, J.L.; Graziani, F.; et al. An investigation to enhance understanding of the stimulation of weed seedling emergence by soil disturbance. Weed Res. 2014, 54, 1-12. [CrossRef]

23. Loddo, D.; Vasileiadis, V.P.; Masin, R.; Zuin, M.C.; Zanin, G. Inhibiting effect of shallow seed burial on grass weed emergence. Plant Prot. Sci. 2016, 52, 64-69. [CrossRef]

24. Kruidhof, M.H.; Bastiaans, L.; Kropff, M.J. Cover crop residue management for optimizing weed control. Plant Soil 2009, 318, 169-184. [CrossRef]

25. Bernstein, E.R.; Stoltenberg, D.E.; Posner, J.L.; Hedtcke, J.L. Weed community dynamics and suppression in tilled and no-tillage transitional organic winter rye-soybean systems. Weed Sci. 2014, 62, 125-137. [CrossRef]

26. Benech-Arnold, R.L.; Sánchez, R.A.; Forcella, F.; Kruk, B.C.; Ghersa, C.M. Environmental control of dormancy in weed seed banks in soil. Field Crop Res. 2000, 67, 105-122. [CrossRef]

27. Oreja, F.H.; De la Fuente, E.B.; Fernandez-Duvivier, M.E. Response of Digitaria insularis seed germination to environmental factors. Crop Pasture Sci. 2017, 68, 45-50. [CrossRef]

28. Thompson, K.; Grime, J.P. A comparative study of germination response to diurnally fluctuating temperatures. J. Appl. Ecol. 1983, 20, 141-156. [CrossRef]

29. Norsworthy, J.K. Soybean canopy formation effects pitted morningglory (Ipomoea lacunosa), common cocklebur (Xanthium strumarium), and sicklepod (Senna obtusifolia) emergence. Weed Sci. 2004, 52, 954-960. [CrossRef]

30. Loddo, D.; Masin, R.; Gasparini, V.; Meggio, F.; Pitacco, A.; Zanin, G. Assessing microclimate conditions of surface soil layers to improve weed emergence modelling. Ital. J. Agrometeorol. 2015, 20, 19-26.

31. Holm, L.G.; Pancho, J.V.; Herberger, J.P.; Plucknett, D.L. A Geographical Atlas of World Weeds, 1st ed.; John Wiley and Sons: New York, NY, USA, 1979; p. 391. ISBN 0471043931. 
32. WIKTROP. Weed Identification and Knowledge in the Tropics. Available online: https://portal.wiktrop.org/ (accessed on 6 March 2019).

33. Ngo, T.D.; Krisnan, M.; Boutsalis, P.; Gill, G.; Preston, C. Target-site mutations conferring resistance to glyphosate in feathertop Rhodes grass (Chloris virgata) populations in Australia. Pest Manag. Sci. 2018, 74, 1094-1100. [CrossRef] [PubMed]

34. Bracamonte, E.R.; Fernández-Moreno, P.T.; Bastida, F.; Osuna, M.D.; Alcántara-de la Cruz, R.; Cruz-Hipolito, H.E.; de Prado, R. Identifying Chloris species from Cuban citrus orchards and determining their glyphosate-resistance status. Front. Plant Sci. 2017, 8, 1977. [CrossRef] [PubMed]

35. Holm, L.G.; Plucknett, D.L.; Pancho, J.V.; Herberger, J.P. The World's Worst Weeds. Distribution and Biology, 1st ed.; University Press of Hawaii: Honolulu, HI, USA, 1977; p. 609. ISBN 0824802950.

36. Kottek, M.; Grieser, J.; Beck, C.; Rudolf, B.; Rubel, F. World Map of the Köppen-Geiger climate classification updated. Meteorol. Z. 2006, 15, 259-263. [CrossRef]

37. Borza, J.K.; Westerman, P.R.; Liebman, M. Comparing estimates of seed viability in three foxtail (Setaria) species using the imbibed seed crush test with and without additional tetrazolium testing. Weed Tech. 2007, 21, 518-522. [CrossRef]

38. Bates, D.; Maechler, M.; Bolker, B.; Walker, S. Fitting linear mixed-effects models using lme4. J. Stat Softw. $2015,67,1-48$.

39. Lenth, R. Emmeans: Estimated Marginal Means, Aka Least-Squares Means, R Package Version 1.4; 2019. Available online: https://CRAN.R-project.org/package=emmeans (accessed on 10 September 2019).

40. Hartig, F. DHARMa: Residual Diagnostics for Hierarchical (Multi-Level/Mixed) Regression Models, R Package Version 0.1.0; 2019. Available online: https://cran.r-project.org/web/packages/DHARMa (accessed on 10 September 2019).

41. R Core Team. R: A Language and Environment for Statistical Computing; R Foundation for Statistical Computing: Vienna, Austria, 2017; Available online: http://www.R-project.org/ (accessed on 10 September 2019).

42. Chauhan, B.S.; Manalil, S.; Florentine, S.; Jha, P. Correction: Germination ecology of Chloris truncata and its implication for weed management. PLoS ONE 2018, 13, e0206870. [CrossRef] [PubMed]

43. Ngo, T.; Boutsalis, P.; Preston, C.; Gurjeet, G. Plant development and seed biology of windmillgrass (Chloris truncata) in Southern Australia. Weed Sci. 2017, 65, 395-405. [CrossRef]

44. Ngo, T.; Boutsalis, P.; Preston, C.; Gill, G. Growth, development, and seed biology of feather fingergrass (Chloris virgata) in Southern Australia. Weed Sci. 2017, 65, 413-425. [CrossRef]

45. Ahring, R.M.; Todd, G.W. Seed size and germination of hulled and unhulled bermudagrass seeds. Agron. J. 1978, 70, 667-670. [CrossRef]

46. Evers, G.W.; Parsons, M.J. Temperature influence on seeded bermudagrass germination. Tex. J. Agric. Nat. Resour. 2009, 22, 74-80.

47. Veenendaal, E.M.; Ernst, W.H.O. Dormancy patterns in accessions of caryopses from savanna grass species in South Eastern Botswana. Acta Bot. Neerl. 1991, 40, 297-309. [CrossRef]

48. Thullen, R.; Keeley, P. Seed production and germination in Cyperus esculentus and C. rotundus. Weed Sci. 1979, 27, 502-505. [CrossRef]

49. Benvenuti, S.; Macchia, M.; Miele, S. Quantitative analysis of emergence of seedlings from buried weed seeds with increasing soil depth. Weed Sci. 2001, 49, 528-535. [CrossRef]

50. Chauhan, B.S.; Singh, R.G.; Mahajan, G. Ecology and management of weeds under conservation agriculture: A review. Crop Prot. 2012, 38, 57-65. [CrossRef]

51. Nwosisi, S.; Nandwani, D.; Hui, D. Mulch Treatment effect on weed biomass and yields of organic sweetpotato cultivars. Agronomy 2019, 9, 190. [CrossRef]

52. Kruidhof, H.M.; Gallandt, E.R.; Haramoto, E.R.; Bastiaans, L. Selective weed suppression by cover crop residues: Effects of seed mass and timing of species' sensitivity. Weed Res. 2011, 51, 177-186. [CrossRef] 
53. Royo-Esnal, A.; Recasens, J.; Garrido, J.; Torra, J. Rigput Brome (Bromus diandrus Roth.) management in a no-till field in Spain. Agronomy 2018, 8, 251. [CrossRef]

54. Rey-Caballero, J.; Royo-Esnal, A.; Recasens, J.; González, I.; Torra, J. Management options for multiple herbicide-resistant corn poppy (Papaver rhoeas) in Spain. Weed Sci. 2017, 65, 295-304. [CrossRef]

(C) 2019 by the authors. Licensee MDPI, Basel, Switzerland. This article is an open access article distributed under the terms and conditions of the Creative Commons Attribution (CC BY) license (http://creativecommons.org/licenses/by/4.0/). 